\title{
High Innovativeness of SMEs and the Configuration of Learning-by-Doing, Learning-by-Using, Learning-by-Interacting, and Learning-by-Science: a Regional Comparison Applying Fuzzy Qualitative Comparative Analysis
}

\section{Tatjana Bennat ${ }^{1}$}

Received: 21 September 2020 / Accepted: 14 February 2021 / Published online: 11 April 2021

(c) The Author(s) 2021

\begin{abstract}
This paper proposes a holistic approach for investigating high innovation performance in SMEs by comparing different German regions. Invoking insights from the innovation mode concept and existing literature on regional innovation, we apply a qualitative comparative analysis (QCA) of 47 interviews with SMEs to show that high innovativeness is based on a bundle of conditions summarized as mechanisms of learning-by-doing, learning-by-using, learning-by-interacting, and learning-byscience. The results indicate that only parts of the DUI mode, in combination with the STI mode, can explain high innovativeness. This has implications for managers as well as for innovation policy, highlighting that there is no universal "best way" to become highly innovative.
\end{abstract}

Keywords Combinatorial knowledge $\cdot$ DUI $\cdot$ Innovation mode $\cdot$ STI

\section{Introduction}

Innovation is a primary source of competitive advantages and therefore an important research topic in economic geography. According to contemporary innovation concepts, the innovation process is based on many feedback loops among users, researchers, and innovators (Kline \& Rosenberg, 1986). This interpretation also stipulates that innovation need not be the result of scientific research-and-development (R\&D) per se; rather, it also occurs through co-creation with users, suppliers, or via firm-internal learning. Knowledge generation involves a variety of actors (Asheim et al., 2016),

Tatjana Bennat

bennat@wigeo.uni-hannover.de

1 Institute of Economic and Cultural Geography, Leibniz University Hannover, Schneiderberg 50, 30167 Hannover, Germany 
also driven by unique regional framework conditions (Boschma, 2005; Strambach \& Klement, 2012), indicating that knowledge and innovation processes have become increasingly complex, interactive, and cumulative. Jensen et al. (2007) conceptualize two fundamental ways of innovating: the "Science, Technology and Innovation (STI) mode" and the "Doing, Using and Interacting (DUI) mode." However, studies on innovation modes are inconclusive as to which mode (or combination) might be the most effective for innovation performance (Apanasovich, 2016; Haus-Reve et al., 2019; Nunes \& Lopes, 2015; Parrilli \& Elola, 2012; Parrilli \& Heras, 2016). Debate continues as to whether DUI and STI are complements or substitutes (Chen et al., 2011; Haus-Reve et al., 2019; Thomä \& Zimmermann, 2019). Furthermore, little is known about the individual components of DUI mode learning. Previous studies treated "DUI" as an abstract shell of learning mechanisms covered by diverse and interchangeable variables (Aslesen et al., 2012; Nunes \& Lopes, 2015; Trippl, 2011; Trott \& Simms, 2017). However, we argue that it is worth breaking the DUI mode into its core mechanisms to learn what constitutes the causal "recipes" for organizational learning that lead to high innovation performance in a specific region.

This question is addressed in the context of innovation activities in small- and medium-sized enterprises in three German regions. Invoking insights from the innovation mode concept and economic geography literature on regional innovation, we propose that high innovation performance does not depend on specific conditions, but rather on a specific configuration of conditions - that is, high innovativeness is based on a bundle of conditions summarized as mechanisms of learning-by-doing, learning-by-using, learning-by-interacting, and learning-by-science.

The complexity of innovation activities necessitates a research design that allows for extending, modifying or revising theoretical structuring and hypothesis during the research process (Mayring, 2002), and thus a circulation between theory and method. During innovation processes, complex and diverse mechanisms come into effect. A qualitative comparative analysis (QCA) is an instrument able to deal with such complexity (Rutten, 2020b).

QCA is a set-membership analytical instrument appropriate for complex configuration analysis (Ragin, 2009). This method uses Boolean algebra rules to provide combinatorial explanations for small-N analysis (Amenta \& Poulsen, 1994). Thus, it expects causal heterogeneity, assuming that different condition combinations (i.e., learning mechanisms) may influence a specific outcome (high innovativeness), rather than individual conditions per se (Ordanini et al., 2014). Hence, this paper intends to contribute to the question of which combinations of learning mechanisms lead to high innovation performance in SMEs by applying a QCA, which is a relatively new instrument in this field as well as in economic geography.

A deeper understanding of how SMEs learn and transfer knowledge into innovations is extremely important for adjusting innovation policy to the needs of SMEs (Aslesen \& Pettersen, 2017; Coletti, 2010; Cooke, 2014; e.g. Isaksen \& Karlsen, 2013). Thus, this paper holds implications for the following: (a) SMEs themselves, and how the focus on specific configurations of learning can help find an effective innovation strategy; however, the analysis also shows alternative, potentially successful "recipes" for high innovation performance, reducing the risk of implementing putative "best practices" that do not fit a firm's setting; (b) regional innovation 
policy searching for instruments to foster innovation activities in SMEs; and (c) measurement of innovations based on DUI-mode learning.

This paper intends to answer two research questions:

1. Which configuration of learning-by-doing, learning-by-using, learning-by-interacting, and learning-by-science leads to high innovation performance in SMEs?

2. How and why do these configurations differ at a regional level?

This paper is organized as follows: the "Theory and Literature Review" section presents the conceptual framework and introduces possible conditions for high innovation performance. After presenting the research design and QCA procedure in the "Method" section, findings are reported in the "Results" section. The "Discussion of QCA Results and Subsequent Case Analysis" section discusses the findings and implications. Finally, a conclusion is made.

\section{Theory and Literature Review}

Underlying theoretical assumptions for this QCA are based on the innovation mode approach and regional innovation models such as regional innovation systems and relational approaches, and on earlier empirical findings of innovation research and our own findings from previous analyses of the same interview material. This is necessary practice for QCA as its causal claims rely on interpretation, which is based on triangulation with substantive empirical and theoretical knowledge (Rutten, 2020a). A core element of QCA is to analyze possible necessary and/or sufficient conditions for a specific outcome in order to reveal causal complexity. This paper aims to analyze innovativeness, which we define as "the implementation of a new or significantly improved product (good or service), or process, a new marketing method, or a new organizational method in business practices, workplace organization or external relations" (OECD 2005, p. 46). Selection of conditions expected to explain the outcome are guided by theory and former case knowledge, constituting an iterative process of model-building (Amenta \& Poulsen, 1994; Greckhamer et al., 2018). Thus, for model-building, different ways of innovating are identified and described in the following, introducing the four condition variables expected to explain high innovation performance: learning-by-science, learning-by-doing, learning-by-using, and learning-by-interacting. The configurational rationale of conditions is explained as follows:

\section{Learning in the STI Mode}

According to Jensen et al. (2007), different processes of idea-finding and innovation processes exist: STI and DUI mode of innovation. Closely related to the knowledge base approach (Asheim \& Gertler, 2005; Manniche, 2012), both leading to innovation performance. 
The STI mode relies on production and exploitation of scientific knowledge usually codified and based on know-what and know-why. This analytical knowledge is usually developed by searching and researching (Manniche, 2012) at universities, by R\&D departments, or in cooperation with research institutions (Johnson et al., 2002). Traditional innovation research often used patent or R\&D investment data to measure learning-by-science (Grillitsch et al., 2019). However, current research shows there are further mechanisms used to integrate scientific knowledge into innovation processes, like seeking analytical knowledge through trade magazines or scientific journals, training employees or integrating academics, up to R\&D collaboration with research organizations (Alhusen \& Bennat, 2020). Thus, learning-bysearching is not only tied to internal R\&D departments, high-tech sectors or larger firms. It is also used by small and medium-sized firms. Rather, a firm's absorptive capacity to learn from scientific knowledge and to innovate through an STI mode seems to be in the foreground. However, the STI mode of innovation has been generally associated with production of radical innovations (Nunes \& Lopes, 2015).

\section{Learning in the DUI Mode}

In contrast, innovations in the DUI mode are based on the application of mostly tacit and synthetic knowledge with a focus on know-how and know-who (Jensen et al., 2007; Johnson et al., 2002). Learning is more informal and conducted through doing, using, and interacting. However, the definition and operationalization of the core learning mechanism of doing, using, and interacting are inconclusive. Jensen et al. (2007) proposed a holistic concept of the DUI mode, explaining that learning-by-doing and learning-by-using both "involve interaction between people and departments" (Jensen et al., 2007, p. 684). Nevertheless, most quantitative studies aim to measure DUI innovativeness based on a firm's internal or (more commonly) external interactions (Apanasovich, 2016), using indicators of either learning-bydoing, learning-by-using, and learning-by-interacting as representative for the DUI mode of innovation (see for overview Alhusen et al., 2019; González-Pernía et al., 2015; Parrilli \& Heras, 2016). Nevertheless, the learning mechanisms of DUI differ in many aspects (e.g., actors involved, firm-internal and firm-external processes, and usefulness at different stages of innovation processes).

Therefore, it is worth breaking the DUI mode into its core learning mechanisms, according to the detailed definition of what constitutes each learning facet suggested by Alhusen et al. (2019):

Learning-by-doing is defined by learning from experienced workers as well as organizational structures fostering employee involvement in innovation processes (Arrow, 1962; Thompson, 2010). However, not only formal organizational structures but also informal institutions like openness to learn from trial-and-error or an innovation-friendly culture influence learning-by-doing (Bennat, 2020). It is strongly associated with firm-internal interacting (i.e., knowledge creation and sharing mechanisms inside a firm). Firm-internal interacting is therefore conceptually close to learning-by-doing but is sometimes considered a separate learning process in the 
literature (Apanasovich, 2016). However, we conflate these two mechanisms in order to emphasize the differentiation between firm-internal and -external learning.

Learning-by-using is defined as learning from customers or final users of a product or service who report the experience of using the product or service (Rosenberg, 1982), or who approach a firm to invent a product or service aligned with their specific needs (Alhusen et al., 2019). Such feedback provides the basis for knowledge accumulation and innovation opportunities from outside the firm. Firms use this learning mechanism to modify or re-design existing products/services or to develop new ones (Alhusen et al., 2019; Rosenberg, 1982). Thus, integrating users can vary across a spectrum from "just stating an idea" to "active involvement in the innovation process and cooperation."

Learning-by-interacting is the product of firms' external interactions with suppliers, competitors, firms from other sectors, consultancies, or industrial associations (Alhusen et al., 2019; Apanasovich, 2016; Johnson, 2010). Thus, external interaction captures all external, non-science-based actors who are not customers. This interaction includes informal and formal exchange of ideas and cooperation in innovation processes.

Innovation outputs of the DUI mode are often new customer-specific products or incremental in nature due to cost reductions or quality improvements (von Hippel, 2005).

\section{The Configurational Model of High Innovativeness}

Since the seminal paper of Jensen et al. (2007), the main tenet of the literature on innovation modes is that a combination of both modes leads to higher rates of innovation output (Apanasovich et al., 2016, 2017; Chen et al., 2011; Fitjar \& RodríguezPose, 2013; Fu et al., 2013; González-Pernía et al., 2015; Jensen et al., 2007; Nunes \& Lopes, 2015; Parrilli \& Heras, 2016; Thomä, 2017). Also, the literature on innovation collaboration mentions that various partners may provide different types of knowledge, enhancing firms' innovation potential (Bennat \& Sternberg, 2020; Cooke, 2012; Strambach \& Klement, 2012). Combining scientific and supply-chain synthetic knowledge thus fosters firm-level innovativeness, and different knowledge types are mostly regarded as complementary. However, Haus-Reve et al. (2019) criticize that those studies only focus on additive rather than multiplicative effects of combining STI and DUI. Their analysis of Norwegian firms revealed a negative interaction between scientific and supply-chain collaboration for product innovation, implying that they are substitutes rather than complements. These findings challenge the dominant tenet asserting the benefits of combining different knowledge types. Nevertheless, their analysis only includes collaborations with actors having different knowledge bases, influencing product innovation. It remains unclear whether a combination of DUI and STI learning mechanisms (which are more than collaborations as discussed in the former section) will also point in the same direction. Former cluster analyses report that the combination of innovation modes is connected with higher levels of innovation performance. However, its definitions, the indicators used (especially for DUI), and interpretations still differ. In sum, multiple ideas exist regarding what constitutes a combinatorial innovation mode. 
There is a scarcity of studies that could answer the question: Which concrete learning mechanism contributes to high innovativeness? Again, it is worth differentiating between the learning mechanisms of DUI due to their substantial differences in actors involved and applied innovation micro-processes (Alhusen et al., 2019). However, as the original idea of the DUI mode is a holistic view of mechanisms, we expect a strong interdependence between learning-by-doing, learning-by-using, and learning-by-interacting. This expectation is also based on our previous studies of the analyzed SMEs, indicating that ideal types of innovation modes hardly exist in practice. This aligns with Isaksen and Karlsen (2010), who argued that innovation modes are not found in pure forms (Aslesen \& Pettersen, 2017; Holtskog, 2017), but it is unclear whether this implies that "doing more of all" is a successful strategy for innovation in SMEs (Haus-Reve et al., 2019).

Based on these theoretical concepts and previous empirical research, our research framework posits that high innovativeness depends on four learning mechanisms (learningby-searching, learning-by-doing, learning-by-using, and learning-by-interacting) implying the following general propositions:

Proposition 1 Disparate configurations of conditions are equifinal in explaining high innovativeness.

Proposition 2 The same condition can either foster or inhibit high innovativeness, depending on how it is configured with other conditions.

Innovation processes are therefore complex, while micro-processes seem to influence each other. Nevertheless, there exists a bias in theory and policy-making that neglects innovation developed through a DUI mode, which may partly be explained by the STI focus on innovation measurement (Jensen et al., 2007; Laestadius, 1998). This can be observed, for example, in the trend of technology transfer activities, the continuous improvement of R\&D infrastructure, and political trials to connect DUI firms with STI partners to increase their innovation output (Cooke, 2014; Isaksen \& Karlsen, 2010). Without an internal R\&D department, learning-by-science is less likely to occur (Amara et al., 2008; Cohen \& Levinthal, 1989). Therefore, the integration of STI into non-R\&D firms is an important goal of current innovation policy, actively effecting innovation processes (e.g., BMBF, 2018). Furthermore, statefinanced regional innovation consultancies can be important interacting partners in DUI mode innovation processes: giving advice for improving firm-internal innovation processes, establishing connections with other actors, counseling during funding applications and increasing firms' visibility through hosting innovation awards and network events (Alhusen et al., 2019).

Hence, we assume that political authorities have been-and are increasinglydesigning regional framework conditions. This assumption aligns with the literature on regional innovation systems (RIS) (Asheim et al., 2016): highlighting the role of regional policy in innovation processes, research from this field calls for tailor-made support strategies, recognizing the existing regional innovation structure (Martin et al., 2011) and its historical contingency (Asheim et al., 2011). Furthermore, the given R\&D infrastructure, as well as regional financial incentives and subsidies, does differ between regions. This is also true for regional facilitators, competencies and networks. 
That means, being embedded in a specific region, firms' locations may also influence innovation processes, strategies and finally, the applied bundle of learning mechanisms. But it is not geographical concentration alone that might explain regional innovation processes. Rather, its conceptual connection with social spaces manifested in institutions (Lenz \& Glückler, 2020), networks and communities might complete the argument of regional innovation. According to the relational approach to economic geography, the focus on micro-level interactions of individuals as principal agents of knowledge creation highlights the connection of social and physical spaces (Bathelt $\&$ Glückler, 2018). From this relational perspective, location determines access to local and global knowledge. For example, at research centers, campuses, conference venues or cultural facilities, physical and social spaces become connected through the co-presence of individuals, allowing the exchange of tacit knowledge through face-toface communication (Rutten, 2017). Thus, hosting those venues, a diverse economic and social-culture and further characteristics of social spaces like shared norms, values, routines and trust informally coordinate the mechanism of knowledge exchange. Clearly there are different approaches to explaining regional innovation. However, they all share knowledge exchange, and thus, innovation processes might differ between regions. Therefore, we assume these regional differences are also visible in configurations of conditions, ending in Proposition 3:

Proposition 3 Configurations of conditions explaining high innovativeness differ between regions.

\section{Method}

\section{Sampling of Cases}

Sampling in qualitative research does not purpose representativeness of findings for (larger) populations. Rather, cases are deliberately selected for constructing a corpus of empirical examples for studying the phenomenon of interest. The sample should capture the variation and variety in the phenomenon under study as far as possible (Flick, 2018). Therefore, a more "loose design" (Miles \& Huberman, 1994) is appropriate when theoretical concepts are under-developed (like the innovation mode concept), with openness and flexibility as needed (Flick, 2018). The original goal of sampling was to cover multiple possible DUI micro-processes. Therefore, we followed a purposive sampling strategy seeking cases that assert themselves as innovative. The sample of interviews was not originally intended to meet the purpose of QCA, which would be to find cases covering all possible combinations of conditions. However, this instrument also worked well for our sample. Only two interviews lacked information about all conditions we tested; those were, consequently, excluded from the QCA procedure.

Hence, 47 interviews with firm's representative of SMEs are included in the QCA procedure. The face-to-face interviews were collected between February 2018 and 


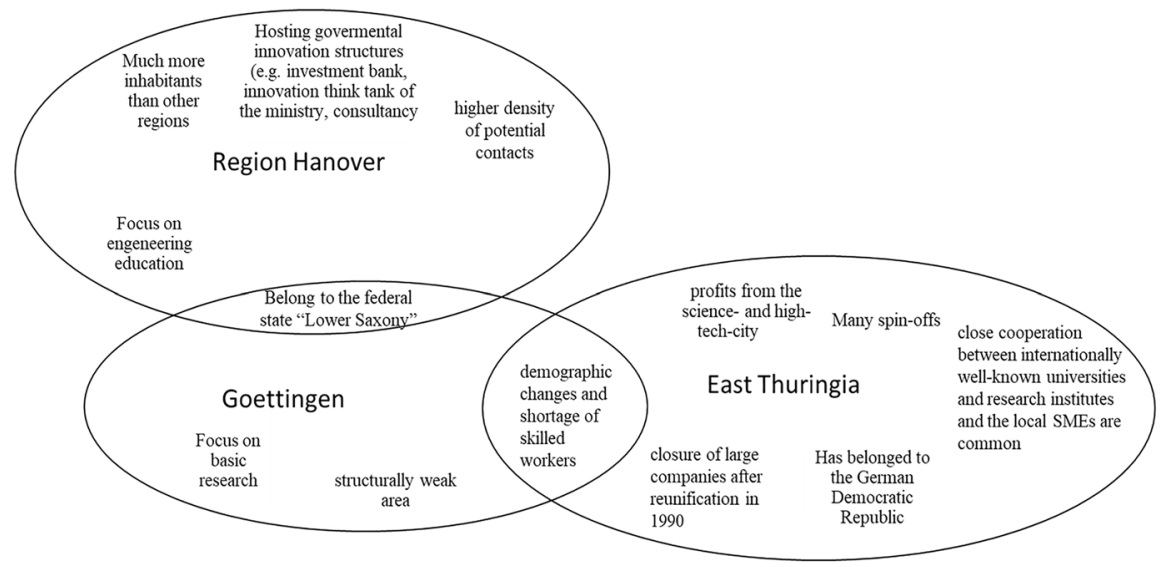

Fig. 1 Details of the three sample regions

October 2018 in the three German "planning regions" (Raumordnungsregionen) ${ }^{1}$ of Goettingen, Hanover, and East Thuringia ${ }^{2}$ to cover three different RISs. The regions all include metropolitan areas, implying that they are "organizationally thick" (Isaksen \& Trippl, 2017, p. 125) RISs. They are characterized by a high number of SMEs, albeit they are orientated at different specializations of the economic structure. Furthermore, they all contain universities and research centers, permitting local collaborations with STI partners. For more details about regional specificities, see Fig. 1.

The sample of cases is non-industry-specific in order to reveal patterns of learning mechanisms not exclusive to particular industries (see Supplementary Material Table 9). First, we identified SMEs that presented themselves as innovative. This was achieved through (a) extensive Web site analysis; (b) snowball sampling, since interference between the cases could be negated (Schreier, 2007); and/or (c) suggestions of regional innovation consultancies. Interviewees were asked to explain, in detail, what kind of innovations were achieved and how innovation takes place in their companies. Anonymity was ensured for all interviewees. After theoretical saturation (Glaser \& Strauss, 1967), using the transcribed interviews, core processes important for the innovation output were examined via content analysis (Mayring, 2010) and ascribed to theoretically derived categories of each innovation mode. For example, statements regarding research cooperation with universities were categorized under STI-mode activities, and statements about knowledge exchange with suppliers were categorized under DUI mode activities-more specifically, "interacting" according to each mode's theoretical definition (see for further information (Bennat, 2020; Alhusen et al., 2021). Most SMEs studied displayed mixtures of processes: STI mode activities and DUI mode activities. Consequently, the researcher

\footnotetext{
1 Functional division of analytical grids in Germany based on districts and commuting flows.

2 Interview Sample: Goettingen: 17 SMEs; Hanover: 15 SMEs; East Thuringia: 15 SMEs.
} 
was familiar with all cases and their micro-processes. We thus gained advanced case knowledge through this analysis before beginning the QCA.

\section{Qualitative Comparative Analysis}

QCA ties together qualitative and quantitative characteristics (Kraus et al., 2012) originally developed for social and political science (Ordanini et al., 2014). However, the practice has also gained attention in innovation research and economic geography for investigating complex phenomena (Kraus et al., 2012; Ordanini et al., 2014; e.g. Rutten, 2019; Valaei et al., 2017). QCA offers insights into which factors (or combinations) are relevant to explaining a specific outcome. By helping to increase the understanding of complementarities and substitutes in configurations (Fiss, 2011; Kraus et al., 2012), QCA can provide new insights for the discussion of combinatorial innovation modes described in the "Theory and Literature Review" section. Advantages of QCA over standard inferential statistical methods include its ability to include combinatorial or conjunctural theories, whereby standard statistical methods face problems of degrees of freedom or multicollinearity. It is open for causal heterogeneity and addresses the problem of "limited diversity" indicating which combinations of conditions empirically exist and which do not. Further, it offers a causally profound discourse about sufficient and necessary conditions (Amenta \& Poulsen, 1994).

As a set-theoretic method, QCA conceptualizes both outcome and conditions as sets, being able to establish logical connections between conditions and outcome. It offers "rules that summarize the sufficiency between subsets of all the possible combination based on their causal conditions (or their complement) and the outcome" (Kraus et al., 2012, p. 17). Each rule represents an equifinal causation to the outcome (represented by the word OR). Thus, QCA does not test effects of independent variables; instead, it employs Boolean algebra to examine relations between an outcome and all binary combinations of causal conditions (Kraus et al., 2012).

Thus, QCA aims to find (combinatorial) conditions which simply describe all cases. Causal explanation follows from substantively interpreting empirical patterns on the basis of case-based and contextual knowledge. Thus, observed cross-case regularities must be checked by the question: How and why does conditions' presence make the outcome possible (Ragin, 2008; Rutten, 2020a)? Analysis of sufficient and necessary conditions is at its base. A condition is sufficient if no case exists where the condition is present, but not the outcome. That is, the configuration of conditions is a logical subset of the outcome. Sufficiency is, therefore, violated by cases presenting a condition (X) and the absence of the outcome (Y) (X, Y cases) (Rutten, 2019). A condition is necessary if there is no case presenting the outcome but not the condition. That is, necessity means that all cases with the outcome also have the condition, but not all cases with the condition also have the outcome. That is, the condition is a superset of the outcome. Table 1 defines necessary and sufficient conditions.

However, due to the complexity of social reality and potential measurement error, QCA emits consistency rates to allow inconsistent cases before neglecting sufficiency (or necessity) (Rutten, 2019). It is good QCA practice to establish different 
Table 1 Evaluation of necessary and sufficient conditions

\begin{tabular}{llll}
\hline Condition is & Condition X & Outcome Y & Evaluation \\
\hline Necessary & 0 & 0 & Allowed (but less relevant) \\
Necessary & 0 & 1 & Not allowed \\
Necessary & 1 & 0 & Allowed (but less relevant) \\
Necessary & 1 & 1 & Allowed \\
Sufficient & 0 & 0 & Allowed (but less relevant) \\
Sufficient & 0 & 1 & Allowed (but less relevant) \\
Sufficient & 1 & 0 & Not allowed \\
Sufficient & 1 & 1 & Allowed \\
\hline
\end{tabular}

Own elaboration based on Blatter et al. (2007)

consistency thresholds for necessity and sufficiency analyses. For necessity analysis, the threshold should be above 0.90 , connected with a high coverage indicating that the potentially necessary condition is empirically relevant (Greckhamer et al., 2018). Coverage represents conditions' empirical relevance or importance for an outcome (Kraus et al., 2012). If $\mathrm{X}$ were a trivial explanation for $\mathrm{Y}$, the coverage-and thus, the proportion of Y-cases covered by X-cases-would be very low (Rutten, 2019).

The application of QCA is structured by (i) definition of property space and development of set-membership measures, (ii) evaluation of consistency in set relations, and (iii) logical reduction. After QCA, solution terms are traced back to cases, which are covered from this solution's terms, including a subsequent content analysis after QCA procedure. This structure is used to present the results in the next section.

\section{Results}

\section{The Property Space and Development of Set-Membership Measures}

This study employs learning mechanisms involved in innovation processes in SMEs identified by the literature: learning-by-science, learning-by-doing, learning-byusing, and learning-by-interacting. Accordingly, the property space consists of all combinations of binary states (presence or absence) of the four conditions that could explain high innovation performance (i.e., $2^{\wedge} 4=16$ combinations).

Calibration - that is, the process of determining a case's membership in the sets of outcome and conditions (Ragin, 2008) — is a half-conceptual, half-empirical process (Greckhamer et al., 2018). Thus, the original micro-learning processes of each case must be transformed into membership scores reflecting the extent to which each SME can be considered a member of the different sets (outcome and conditions). Applying a fuzzy-set calibration approach, ${ }^{3}$ membership scores vary from 1 (full

\footnotetext{
3 Instead of a binary crisp-set QCA conventionally based on Boolean algebra, where a case is either in or out of a set, with 1 indicating membership and 0 indicating non-membership. Fuzzy sets extend crisp sets by allowing membership scores in the interval between 0 and 1 Ragin (2017).
} 
Table 2 Calibration of conditions

\begin{tabular}{lll}
\hline Condition (learning mechanism) is & 1 & Regularly used for innovation processes \\
0.8 & Often used for innovation processes \\
0.6 & Now and then used for innovation processes \\
0.5 & Not affecting innovation processes that much \\
0.4 & Seldom used for innovation processes \\
0.2 & Applied but not (jet) used for innovation processes \\
0 & Not used at all \\
\hline
\end{tabular}

membership) to 0 (full non-membership in the set), pinpointing qualitative states (Ragin, 2009). The score of 0.5 indicates the cross-over point and maximum ambiguity (Kraus et al., 2012), that is not assigned in practice. The calibration process requires substantial knowledge of theory (see the "Theory and Literature Review" section) and cases to specify the applied breakpoints. This is given by the fact that interviewer and researcher are congruent and that the same interview material was previously subjected to content analysis. A sign of quality in QCA procedure is transparent calibration. Therefore, the breakpoints (Table 2) will be explained and clarified through interview quotes.

\section{Condition 1: Learning-by-Science}

For calibrating learning-by-science, we included statements about use of scientific journals, implementing scientific theory, scientific training of employees or learning from academics, and R\&D cooperation with universities or research institutes. Further, the evaluation of those processes and "how much" was learned was considered for scoring.

The following quote represents a score of 1 :

"I have researched around many topics and earned great methodological competencies. [...] This big data idea was born during my $\mathrm{PhD}$. [...] we are able to do predictive maintenance or condition monitoring, because we were integrated in many scientific research projects before. [...] I'm still close to my doctoral adviser. We meet regularly, organize events together and discuss how we can bring together research and practice. [...] We also publish together, which is an important source for this firm, because [...] the original idea is to bring together science and practice. [...] university is also an important pool for new employees." (F32)

\section{Condition 2: Learning-by-Doing}

To calibrate learning-by-doing, we extracted statements from interviews regarding learning through development or integration of new technology or machinery (hands-on-learning), training employees, openness to learning from trial-and-error, perceived innovation culture, and internal knowledge exchange. Clearly, for the 
scoring decision, it is necessary to include not only the presence of a learning mechanism, but also its evaluation for innovation processes.

The following quote represents a score of 0.8 :

"I implemented a helpful error culture. R. and I, we bluntly tell each other if we see something foolish, give feedback and thereby develop further. We follow this American thinking: 'let's quickly fail and then quickly learn.' To develop products the market needs, I need both error and feedback. And then the openness to learn from them." (F19)

The following quote represents a score of 0.2 :

"We have to do advanced training. I perceived this as a lot. [...] If we want to apply for funding for a customer, we need to be listed and therefore, we have to do advanced training. [...] From the point of used methods or computer programs we are not very innovative..." (F30)

\section{Condition 3: Learning-by-Using}

Learning-by-using was calibrated through information about the importance of customer interaction for innovation processes and whether the firm actively sought customer feedback.

The following quote represents a score of 0.6:

"Interviewee: [The innovation was developed] because of clinical necessaries. There where undesirable side effects. [...] we also ask customer about satisfaction during treatment process via questionnaires. [...] depending on the idea we also build prototypes.

Interviewer: Do you also integrate customers in prototype testing processes?

Interviewee: No." (F22)

\section{Condition 4: Learning-by-Interacting}

To calibrate learning-by-interacting, we analyzed statements about suppliers' roles, interactions with non-competitor firms from the same sector, firms from other sectors, private and state-financed consultancies, and networks used for innovation processes. Statements about competitors were excluded, because we found an overall pattern in the interview material indicating that competitors were less important for innovation processes. This can be partly explained by Germany's current uncompetitive economic climate (Alhusen et al., 2019).

The following quote represents a score of 0.4 :

"Interviewer: Are there other actors playing a role for novelty processes? Suppliers?

Interviewee: No.

Interviewer: Consultancies, banks? 
Table 3 Calibration of the outcome

\begin{tabular}{llll}
\hline Firm & 1 & Regularly implements innovations & $\begin{array}{c}\text { Indicates } \\
\text { high inno- } \\
\text { vativeness }\end{array}$ \\
0.8 & Often implements innovations & \\
0.6 & Now and then implements innovations & Indicates \\
0.5 & Innovation processes are more than a single event & average \\
0.4 & Implements one own innovation & innovative- \\
0.2 & Invents own innovation, but market implementation is still unclear & ness \\
0 & Adapts innovation from others, but does not invent own innovations & & \\
\end{tabular}

Interviewee: No, neither. [We got ideas for novelties] through interaction with colleges, industry fairs or trading magazines." (F22)

\section{The Outcome "High Innovativeness"}

According to the definition of innovation in the "Theory and Literature Review" section, the outcome's calibration includes all innovation types (product, process, marketing, and organizational), whether they are radical or incremental. Because our sample of cases only includes firms describing themselves as innovative, we have no information about cases which are not innovative. Due to this sampling peculiarity, we are unable to calibrate data for not being innovative (presence vs. absence of "innovative" outcome). However, it was possible to differentiate between levels of innovativeness. Thus, the cross-over point of 0.5 indicates the threshold between high innovativeness and average innovativeness, as our sample only includes SMEs which, at least, adapt innovation generated by others, which we ranked at the bottom of innovativeness (see Table 3).

After calibration, a matrix is displayed, characterizing all cases after their scoring in each condition as well as the outcome (see Supplementary Material Table 10). All subsequent steps are based on this matrix.

\section{Evaluation of Consistency in Set Relations}

The next QCA task is evaluating whether a condition is necessary for the existence of the outcome. Adhering to Greckhamer et al. (2018), we applied a threshold of 0.90 for consistency. We applied this analysis for all cases together using fsQCA software. Results show that neither the presence of all conditions chosen nor their absence (highlighted with $\sim$ ) are a necessary condition to explain the "high innovativeness" outcome. Table 4 represents consistency and coverage rates for all cases together. Rates for learning-by-doing and learning-by-using are relatively high and near 0.90 . However, this may indicate that learning-by-doing and learning-byusing are highly important for high innovativeness, but not necessary.

We analyzed configurations for the absence (negation) of the outcome separately. Thus, the occurrence of high innovativeness and average innovativeness (which represents the negation of high innovativeness) may constitute two qualitatively different phenomena. Analysis reveals that also no condition is necessary 
Table 4 Analysis of necessary conditions

\begin{tabular}{lll}
\hline & Consistency & Coverage \\
\hline Doing & 0.835 & 0.773 \\
Using & 0.835 & 0.779 \\
Interacting & 0.734 & 0.850 \\
sti & 0.741 & 0.858 \\
doing & 0.468 & 0.765 \\
using & 0.439 & 0.710 \\
interacting & 0.612 & 0.739 \\
$\sim$ sti & 0.583 & 0.704 \\
\hline
\end{tabular}

to explain average innovativeness. For all cases, $\sim$ interacting and $\sim$ sti appear very important, but their rates remain below the 0.90 threshold, indicating that the relationship is not symmetrical, as the presence of learning-by-sti and learning-by-interacting is not necessary, nor even particularly important, for the presence of high innovativeness.

In the following, we evaluate which configuration may be regarded as sufficient for high innovativeness. Based on membership scores, sub-set relations can be analyzed by the truth table using Boolean algebra (Ragin, 2008). The truth table (Table 5) represents all logically possible configurations of these conditions' presence and absence; we have 16 configurations (rows). The "number" shows the case frequency, with membership above 0.5 in that corner of the vector space (Ragin, 2017). A threshold of at least one case is applied (Greckhamer et al., 2018). The "outcome" indicates which configurations lead to positive results. Outcome was defined as "true" ( $1=$ consistent subset of the outcome) if consistency was above 0.90 , which is based on a substantial gap in consistency scores (Ragin, 2009). The truth table shows that only two of the 16 possible configurations of conditions for high innovativeness do not exist in the sample including all cases (so-called logical reminders). This yields seven "true" rows, seven "false" rows, and two logical reminders. Thus, rows with zero-cases must be deleted. However, they are included in intermediate solutions, as the researcher can test different assumptions about reminders based on theoretical and case knowledge.

\section{Logical Reduction}

Next, the 14 configurations of the four learning mechanisms are minimized based on a Quine-McClusky algorithm (Rille-Pfeiffer, 2009). Reducing the truth table generates result terms, the easiest paths to explain the outcome. For analysis of high innovativeness of all cases, three equifinal configurations are found, which underline Proposition 1:
a) doing*sti
b) interacting*sti
c) doing*using*interacting 
Table 5 Truth table of all cases together

\begin{tabular}{lllllll}
\hline Doing & Using & Interacting & STI & Number & Innovation & Raw consistency \\
\hline 0 & 1 & 1 & 1 & 2 & 1 & 0.95918 \\
1 & 0 & 1 & 1 & 1 & 1 & 0.95652 \\
0 & 0 & 1 & 1 & 1 & 1 & 0.94737 \\
1 & 1 & 1 & 1 & 13 & 1 & 0.92857 \\
1 & 1 & 0 & 1 & 4 & 1 & 0.92857 \\
1 & 0 & 0 & 1 & 1 & 1 & 0.91304 \\
1 & 1 & 1 & 0 & 5 & 1 & 0.91045 \\
1 & 1 & 0 & 0 & 1 & 0 & 0.88235 \\
0 & 1 & 0 & 1 & 4 & 0 & 0.875 \\
1 & 0 & 1 & 0 & 5 & 0 & 0.87037 \\
0 & 0 & 0 & 1 & 1 & 0 & 0.85366 \\
1 & 0 & 0 & 0 & 2 & 0 & 0.81448 \\
0 & 1 & 0 & 0 & 4 & 0 & 0.81356 \\
0 & 0 & 0 & 0 & 3 & 0 & 0.74 \\
0 & 0 & 1 & 0 & 0 & delet & \\
0 & 1 & 1 & 0 & 0 & delet & \\
\hline
\end{tabular}

Table 6 summarizes full empirical results.

These solution terms are robust in the case of prime implicants ( doing*interacting vs. interacting*sti) and for the assumption that all conditions are present vs. no assumptions. The high solution consistency (above 0.88) underlines the model's strength. The high solution coverage (above 0.77 ) shows that many memberships in the outcome are explained by the solution terms. Raw coverage indicates that between 0.62 and 0.67 of memberships in the outcome are explained by each configuration term. The proportion of cases covered uniquely by a specific configuration is displayed by the unique coverage scores (memberships that are not covered by other solutions terms), which are always very low (Schneider \& Wagemann, 2012). Thus, the first term (doing*sti) appears slightly more important for high innovativeness, as its raw coverage is the highest (0.67). No single condition is sufficient to explain high innovativeness; rather, combination with other conditions explains the outcome.

Table 6 Analysis of the truth table (intermediate solution with no assumptions)

\begin{tabular}{llll}
\hline & Raw coverage & Unique coverage & Consistency \\
\hline Doing*sti & 0.676 & 0.079 & 0.904 \\
Interacting*sti & 0.626 & 0.029 & 0.926 \\
Doing*using*interacting & 0.633 & 0.072 & 0.898 \\
- & - & - & - \\
Solution coverage & 0.776978 & & \\
Solution consistency & 0.885246 & & \\
\hline
\end{tabular}


Table 7 Distribution of cases covered by solution terms

\begin{tabular}{lllll}
\hline Cases covered by... & $\begin{array}{l}\text { East- } \\
\text { Thuringia }\end{array}$ & Hanover & Goettingen & Total \\
\hline Solely maker & 1 & 2 & 2 & 5 \\
Solely networker & 1 & 0 & 2 & 3 \\
Solely DUI & 0 & 3 & 2 & 5 \\
Maker and networker & 1 & 0 & 0 & 1 \\
All three solution terms & 4 & 5 & 4 & 13
\end{tabular}

Analyzing cases covered by the configurations reveals that many have membership in multiple or all configurations, suggesting that learning mechanisms are complementary rather than competing explanations for high innovativeness. Terms $\mathrm{a}$ and $\mathrm{b}$ also include DUI and STI mechanisms, while term c covers only DUI components. Firms with membership in all configurations include cases possessing their own R\&D departments or cooperating with universities or research institutes. However, they also scored high on DUI mechanisms, using those mechanisms at least occasionally for innovation activity, but with different weights. The configuration of makers' (term a) innovation processes relies on learningby-doing and learning-by-science. This is not exclusively linked to firms with formal R\&D departments. However, they were often members of firm-university cooperation. The networkers' (term b) configurations cover firms scoring high on learning-by-interacting with suppliers, for example, or with other inter-sectoral firms and learning-by-science. The DUIs' (term c) configuration comprises theoretical components of DUI mode literature. DUIs innovate mainly through learning-by-doing, learning-by-using, and learning-by-interacting. It does not mean that they are not familiar with learning-by-science, but it was less important for their innovations.

In other words, high innovativeness appears in different cases because of different causal "recipes," but for most highly innovative firms, all three configurations are logical equifinal explanations for their success. Table 7 gives an overview of case distribution, which can be explained by the solution terms.

This distribution gives a first indication that regional differences may exist between the three sample regions. However, a regional QCA is fruitless, as the truth tables of each region differ, showing between six to eight logical reminders and different configurations, which are covered by cases. Because the truth table of all cases together displayed only two logical reminders, we must assume that the missing configurations for regional analysis were simply not being observed, although they exist in practice. However, this must not be evaluated as indicating too few cases for each region. According to Marx (2006), the proportion of variables to cases should be $<0.33$, which means in our case, five variables (four conditions and one outcome) are acceptable for at least 15 cases per region. Thus, a regional QCA would likely show divergent solution terms, but this cannot be interpreted as indicating different regional mechanisms. Therefore, a subset analysis was performed to check whether the overall configurations are also consistent subsets of high innovativeness for each region. 
Table 8 fsQCA output regional subset analysis

\begin{tabular}{llll}
\hline & Outcome innovation & Consistency & Raw coverage \\
\hline Goettingen & Doing*using*interacting & 0.9394 & 0.5962 \\
& Interacting*sti & 0.9412 & 0.6154 \\
Hanover & Doing*sti & 0.9444 & 0.6538 \\
& Doing*using*interacting & 0.8250 & 0.7500 \\
& Interacting*sti & 0.8571 & 0.6818 \\
East-Thuringia & Doing*sti & 0.8421 & 0.7273 \\
& Doing*using*interacting & 0.9600 & 0.5581 \\
& Interacting*sti & 1.0000 & 0.5814 \\
& Doing*sti & 0.9333 & 0.6512 \\
\hline
\end{tabular}

Subset analysis revealed that overall solution terms are indeed also consistent for each region (see Table 8).

However, consistency rates for East Thuringia were extremely high (nearly 1), while for Hanover, raw coverage was higher than for Goettingen and East Thuringia. This can be explained by the number of cases calibrated as highly innovative, but not covered by the three overall solution terms (three cases each in Goettingen and East Thuringia; two cases in Hanover). Thus, QCA did not reveal regional differences, which does not mean they do not exist.

The analysis for average innovativeness ( $\sim$ innovative) for all regions reveals three equifinal solution terms ( using* $\sim$ interacting; doing* $\sim$ using; $\sim$ using*sti) at 0.78 solution consistency and 0.65 solution coverage. Although those quality criteria are still acceptable, this indicates that the mechanisms chosen are better explanations for high innovativeness than for average innovativeness (see Supplementary Material). It confirms Proposition 2 that the same learning mechanism can either foster or inhibit high innovativeness, depending on how it is configured with other conditions.

\section{Discussion of QCA Results and Subsequent Case Analysis}

Results reveal that multiple processes can explain high innovativeness in SMEs (Proposition 1) and that individual learning mechanisms can foster or inhibit high innovation performance (Proposition 2). Regional subset analysis revealed that configurations of learning mechanisms explaining high innovativeness are also consistent for sampled regions. This study presents new insights into how learning mechanisms, and thus, innovation modes are interrelated, adding an alternative explanation for the (partially) inconclusive literature on combinatorial innovation modes. Results show that only parts of DUI mode together with STI mode can explain high innovativeness. No path was found which indicates that all four learning mechanisms together lead to high innovation performance. Rather, parts of DUI, together with learning-by-science, as well as DUI alone are sufficient conditions for high innovativeness in our sample. However, no learning mechanism was identified as a necessary condition. 
Firms covered by all three logical equivalent configurations either integrated $R \& D$ cooperation at their innovation processes or maintain $R \& D$ departments, detached from firm size (as we also count for $R \& D$ departments if at least one person was responsible for innovation processes) as well as firm age. However, a pattern emerged from interview material: all those firms followed an innovationfriendly strategy (even if it was informal, which is quite often the case in SMEs (Bennat, 2020)) and integrated an innovation culture, allowing for trial-and-error learning. Nevertheless, some SMEs with formal R\&D departments were not covered by all three solution terms. Thus, we conclude that it is not the R\&D department per se; rather it can be an indication for an innovation-friendly mindset and the ability to think in innovation processes.

These strategies, of course, do differ between firms inter alia because of different environments (Martin et al., 2011), histories (Asheim, 1996; Asheim et al., 2011), experiences, markets or CEO characteristics (Bennat, 2020). Therefore, there is no universal "best practice" to become highly innovative, implying that it is not "doing more of all" (Haus-Reve et al., 2019), which explains high innovation performance. Nevertheless, no evidence was found that "doing more of all" explains the negation of high innovativeness, which is average innovativeness. It was, rather, explained through the absence of learning mechanisms.

\section{Prototypical Innovation Mechanism}

QCA reveals only that learning mechanisms must be present to explain high innovativeness, but not whether those mechanisms are also combined in practice. As we allowed interviewees to explain mechanisms of different innovation projects of their firms, scoring did not represent their use in one specific innovation project. In order to interpret the essence of the configuration for high innovativeness, QCA solution terms are qualified by another case-level qualitative analysis. Thus, cases are identified which are covered by each configuration term, complementing a cross-case analysis to report prototypical innovation mechanisms as suggested by Greckhamer et al. (2018) and Ragin (2017).

Further content analysis of makers' interviews (doing*sti), showed that learningby-doing and learning-by-science are indeed combined for a specific innovation. However, those cases typically integrated students (as interns or academic employees) to bring scientific knowledge into the firm, connecting it with expertise of older, more experienced workers at the firm; R\&D cooperation with research institutes was evaluated as unhelpful.

"Yeah, we had some R\&D cooperation projects. But it was a rather bad experience. We did that two, three times. [...] Our experience is that the result is better if you do it by our own [...] I think, it is helpful to have a great mixture of experienced older employees and new knowledge of young employees which they carry out of university. Mixing this knowledge is the optimum." (F38) 
This has implications for innovation consultancies as well as managers. It is not $R \& D$ cooperation itself that fosters high innovativeness. Rather, in more "doing-orientated" firms, integrating students and academics as sources of scientific knowledge proved more fruitful.

Content analysis of networkers (interacting*sti) indicated that those firms participated in ZIM projects ${ }^{4}$ with other firms and research institutes. Thus, we found little evidence in interviews that this connection would exist without this specific promotion instrument of German policy. In all cases, covered solely by this solution, learning-byscience was explained as a helpful knowledge component during the innovation process. However, these firms were relatively close to scientific research (e.g., their customers were universities or their innovation was also based on scientific tests of food-safety or bio-natural gas, for example). Therefore, policy instruments fostered this specific interaction, even if in ZIM projects it is not necessary to include a research institute. This influence, however, is a double-edged sword, as this interviewee explained:

"Yes, we are always interested in those [ZIM] projects, however, especially for this bio natural gas project, the market goes up and down. Funding pops up and disappears, abolished, then restricted and in the end it is unappealingly. This is a heavy problem, sometimes a great pity, if you have invested much money before, also, public resources. And then banks bounce down. From my point of view these are senseless wastages." (F44)

Firms solely configured as DUIs had no formal R\&D departments, being startups and mature firms from service and producing sectors (also high-tech), with only some CEOs having university backgrounds. Interviewees highlighted that learningby-doing, learning-by-using, and learning-by-interacting are indeed combined during innovation processes. Furthermore, according to interviewees, these learning mechanisms are also used in that order during innovation processes. The two following quotes represent this assumption:

"Innovation? Baby steps! I prefer small steps. Big, brilliant invention, like long ago, reclusive at the basement, then after four years development a market release. This is not working anymore. Product life cycles are too short. This means, small steps, find someone for a proof of concept, interact with customers, and then start development in coworking with others." (F20)

"We start from the beginning. We developed an audit method to analyze the real pains of a specific firm. [...] Which problem do they solve and will this problem be relevant in the future? This is the first step. Afterwards, we analyze if the firm indeed resolved this problem. This means: do they offer the right product, do their processes hit the needs. [...] This is what I do before matchmaking [...]. And then we search for start-ups, which could face this problem. If we found some, we connect the firms and organize projects." (F19)

\footnotetext{
4 "ZIM" ("Zentrales Innovationsprogramm Mittelstand") stands for "Central Innovation Program for small and medium-sized enterprises (SMEs)." Funded by the Federal Ministry for Economic Affairs and Energy, it aims to foster innovative capacity of SMEs. It is Germany's largest innovation program for SMEs. (www.zim.de).
} 
However, we found evidence that this was true for product innovation, but not for organizational innovation. The latter were often the result of learning-by-doing alone.

\section{Regional Analysis}

Regional subset analysis revealed that the three overall solution terms are also consistent for each region. Hence, all solution terms include elements of DUI-mode learning mechanisms. This has an important implication for policy support, which nowadays strongly focuses on an STI mode. Thus, learning-by-science is neither necessary nor sufficient to explain high innovativeness in sampled SMEs. Regional innovation policy and consultancy should also recognize their own important role as supporters of firm-internal learning as well as fostering interaction.

Although QCA did not uncover regional differences, some regional peculiarities are found during content analysis of the interviews. Thus, according to Proposition 3 - that results differ for regional analysis-we must assume this proposition is only partially proven by this method.

For example, interviewees in East Thuringia often highlighted the importance of learning-by-interacting and learning-by-science, which is indeed among the solution terms the QCA revealed: analysis of East Thuringia interviews revealed that this is partially explained by the historic structuring of the economy in former East Germany. Interviewees described East Thuringia as still shaped by specialization in optics and medical technology paired with a great variety of applied research institutes. This also has consequences for qualified employees because universities, applied research centers and firms are familiar in related clusters. "Talking the same language" and operating in related markets, coupled with the history of combination structure of economy in the former GDR, means that many SMEs already know-and therefore trust-each other. Further, some interviewees highlighted that many start-ups (or spin-offs) settle near applied research centers. This aligns with the argument of relational approaches emphasizing that shared norms, values, customs, habits, routines, trust, or further forms of relational proximity effectively "glue" individuals together and work as "lubricants" for knowledge exchange (Malecki, 2012), and highlights the informal nature of social space (Bathelt \& Glückler, 2018). However, some formal activities of fostering knowledge exchange were also found. There was evidence in the interviews that in East Thuringia, the concept of "cluster" is highly charged with technology and innovation topics, strongly supported by regional policy. Therefore, many local networks can potentially foster knowledge exchange and cooperation. One interviewee explained three different ways that R\&D cooperation starts:

"Often research institutes approach us about specific cooperation [...]. This is one possible way. A second way is that cooperation is fostered through networks often resulting in research projects. And the third way are, for example, ZIM Projects; there two firms work together with one research institute, developing a specific technology [...] We do all three ways." (F34) 
This quote suggests that innovativeness simply happens to a firm. However, it is hardly determined by its agents. Because of the emergent nature of causality, a learning mechanism's presence lets firms act in ways that make high innovativeness possible. Due to some inconsistent cases, it might be that unobserved causes may negate the willingness/ability of firms to innovate, even when sufficient conditions are present. Causality enables, but never forces an outcome (Rutten, 2020a, b). This is also the case for interacting partners like business consultancies:

"Yes, we have got a specific contact person, who is capable. I think highly of him. He has many contacts, knows everything, what is actually happening and always an interesting interacting partner. This is less institutionalized, it is personal [...] the person matters. Either the person is helpful or not." (F20)

Hence, not only the regional offer of innovation consultants but also their personalities differ between regions. As for Hanover, the overall evaluation of policy support, consultancies and infrastructure enabling cooperation, innovation and growth was perceived as mostly positive by company managers; policy support was particularly criticized for Goettingen:

"The office for economic development just woke up in the last years, now supporting start-ups and so on; 10 years ago, there was nothing! [...]

Because their consultants are quite old and have been working there for a long time. [...] They know nothing more than the internet." (F4)

Nevertheless, this quote also shows the dynamic of regional peculiarities which can enable or inhibit specific learning mechanisms. However, the firm managers interviewed who actively sought to be innovative were capable of compensating for this aspect (e.g., by using economic associations for network activities).

\section{Conclusion}

To define the causal "recipes" for organizational learning that lead to high innovation performance in specific regions, we applied a QCA of 47 SMEs in three different German regions.

The core findings should be consulted for regional innovation policy and managerial questions, which are as follows: (1) no condition is solely necessary nor sufficient to explain high innovativeness. It is rather the combination with other conditions that explains the outcome; a concentration on one learning mechanism would be less successful. (2) There was no evidence that all four learning mechanisms together led to high innovation performance. Rather, parts of DUI, together with learning-by-science, as well as DUI alone, were sufficient conditions for high innovativeness in our sample. This implies that a policy focus on the STI mechanism would neglect a DUI mode of being innovative, which is equally promising for becoming highly innovative. (3) Many 
cases had membership in multiple or all configurations, which suggests that the learning mechanisms are complementary rather than competing explanations for high innovativeness. (4) Finally, the overall solution terms were also stable for different regional contexts, which, however, does not mean that regional peculiarities do not exist, which is an important insight for policy makers when transferring concepts from one region to another. This analysis first showed insights into differences in regional innovation processes. However, a further QCA with more nuanced regional sampling is needed to evaluate whether these peculiarities can be also found in regional solution terms, explaining high innovativeness. Thus, a more tightly designed sample strategy (Flick, 2018) or a larger sample would be useful for applying regional QCA. The latter, however, would especially make a subsequent content analysis, and therefore the integration of QCA results into interview contexts, challenging. Nevertheless, QCA can also expand economic geography methods in order to reveal a different view on regional innovations and is a helpful method for deepening the understanding of the innovation mode concept.

Supplementary Information The online version contains supplementary material available at https://oi. org/10.1007/s13132-021-00774-1.

Acknowledgements Special thanks go to Ruel Rutten, who is an outstanding expert in QCA and extremely helpful advisor to me during QCA procedure as well as to the research team, and the interviewees, for spending their valuable time sharing their deeply interesting insights. Furthermore, I would like to thank all my other colleagues at the Institute for their valuable comments on earlier drafts of this manuscript.

Funding Open Access funding enabled and organized by Projekt DEAL. This work was supported by the German Federal Ministry of Education and Research under Grant 16IFI005; Bundesministerium für Bildung und Forschung.

Data Availability The qualitative data are not publicly available due to restrictions. They contain information that could compromise the privacy of research participants.

Code Availability fsQCA.

\section{Declarations}

Conflict of Interest The authors declare that they have no conflict of interest.

Open Access This article is licensed under a Creative Commons Attribution 4.0 International License, which permits use, sharing, adaptation, distribution and reproduction in any medium or format, as long as you give appropriate credit to the original author(s) and the source, provide a link to the Creative Commons licence, and indicate if changes were made. The images or other third party material in this article are included in the article's Creative Commons licence, unless indicated otherwise in a credit line to the material. If material is not included in the article's Creative Commons licence and your intended use is not permitted by statutory regulation or exceeds the permitted use, you will need to obtain permission directly from the copyright holder. To view a copy of this licence, visit http://creativecommons.org/ licenses/by/4.0/. 


\section{References}

Alhusen, H., \& Bennat, T. (2020). Combinatorial innovation modes in SMEs: mechanisms integrating STI processes into DUI mode learning and the role of regional innovation policy. European Planning Studies, 3(1), 1-27. https://doi.org/10.1080/09654313.2020.1786009

Alhusen, H., Bennat, T., Bizer, K., Cantner, U., Horstmann, E., Kalthaus, M., Proeger, T., Sternberg, R., Töpfer, S. (2021). A New Measurement Conception for the 'Doing-Using-Interacting' Mode of Innovation. Research Policy, 50(4). https://doi.org/10.1016/j.respol.2021.104214

Alhusen, H., Bennat, T., Bizer, K., Cantner, U., Kalthaus, M., Proeger, T., Sternberg, R., \& Töpfer, S. (2019). A new measurement conception for the 'doing-using-interacting' mode of innovation, Research Policy, Volume 50, Issue 4. https://doi.org/10.1016/j.respol.2021.104214

Amara, N., Landry, R., Becheikh, N., \& Ouimet, M. (2008). Learning and Novelty of Innovation in Established Manufacturing SMEs. Technovation 28(7):450-463. https://doi.org/10.1016/j.technovation. 2008.02.001

Amenta, E., \& Poulsen, J. D. (1994). Where to begin: A survey of five approaches to selecting independent variables for qualitative comparative analysis. Sociological Methods \& Research, 23(1), 22-53. https://doi.org/10.1177/0049124194023001002

Apanasovich, N. (2016). Modes of innovation: A grounded meta-analysis. Journal of the Knowledge Economy, 7(3), 720-737. https://doi.org/10.1007/s13132-014-0237-0

Apanasovich, N., Alcalde-Heras, H., \& Parrilli, M. D. (2017). A new approach to business innovation modes: the 'Research, Technology and Human Resource Management (RTH) model' in the ICT sector in Belarus. European Planning Studies, 25(11), 1976-2000. https://doi.org/10.1080/09654313. 2017.1322040

Arrow, K. J. (1962). The Economic Implications of Learning by Doing. The Review of Economic Studies, 29(3), 155. https://doi.org/10.2307/2295952

Asheim, B. (1996). Industrial districts as "learning regions": A condition for prosperity. European Planning Studies, 4(4), 379-400. https://doi.org/10.1080/09654319608720354

Asheim, B., Boschma, R., \& Cooke, P. (2011). Constructing regional advantage: Platform policies based on related variety and differentiated knowledge bases. Regional Studies, 45(7), 893-904. https://doi. org/10.1080/00343404.2010.543126

Asheim, B., \& Gertler, M. S. (2005). The geography of innovation: Regional innovation systems. In J. Fagerberg, D.C. Mowery, \& R. R. Nelson (Eds.), The Oxford Handbook of Innovation (pp. 291317). Oxford University Press.

Asheim, B., Grillitsch, M., \& Trippl, M. (2016). Regional innovation systems: Past-presence-future. In C. Carrincazeaux, D. Doloreux, \& R. Shearmur (Eds.), Handbook on the Geographies of Innovation (pp. 45-62). Edward Elgar Publishing.

Aslesen, H. W., Isaksen, A., \& Karlsen, J. (2012). Modes of innovation and differentiated responses to globalisation-A case study of innovation modes in the Agder region, Norway. Journal of the Knowledge Economy, 3(4), 389-405. https://doi.org/10.1007/s13132-011-0060-9

Aslesen, H. W., \& Pettersen, I. B. (2017). Entrepreneurial firms in STI and DUI mode clusters: Do they need differentiated cluster facilitation? European Planning Studies, 25(6), 904-922. https://doi.org/ 10.1080/09654313.2017.1300238

Bathelt, H., \& Glückler, J. (2018). Wirtschaftsgeographie: Ökonomische Beziehungen in räumlicher Perspektive [Economic Geography. Economic Relations in Spatial Perspective] (4.th ed.). UTB: Vol. 8217. UTB; Verlag Eugen Ulmer.

Bennat, T. (2020). Innovation modes in small and medium-sized firms: organization of learning processes and regional innovation policy implications. Hannover: Gottfried Wilhelm Leibniz Universität, Dissertation. https://doi.org/10.15488/10331

Bennat, T., Sternberg, R., \& [R.], . (2020). Knowledge bases in German regions: what hinders combinatorial knowledge dynamics and how regional innovation policies may help. European Planning Studies, 28(2), 319-339. https://doi.org/10.1080/09654313.2019.1656168

Blatter, J., Janning, F., \& Wagemann, C. (2007). Qualitative Politikanalyse: Eine Einführung in Forschungsansätze und Methoden [Qualitative policy analysis. An introduction of research methods]. VS Verlag für Sozialwissenschaften I GWV Fachverlage GmbH Wiesbaden. https://doi.org/10.1007/ 978-3-531-90716-1 
BMBF. (2018). Forschungs- und Innovationsförderung: Ein Wegweiser für kleine und mittlere Unternehmen [Research and Innovation funding: Guidline for small and medium-sized enterprizes]. Berlin: Bundesministerium für Bildung und Forschung. www.bmbf.de

Boschma, R. (2005). Proximity and Innovation: A Critical Assessment. Regional Studies, 39(1), 61-74. https://doi.org/10.1080/0034340052000320887

Chen, J., Chen, Y., \& Vanhaverbeke, W. (2011). The influence of scope, depth, and orientation of external technology sources on the innovative performance of Chinese firms. Technovation, 31(8), 362-373. https://doi.org/10.1016/j.technovation.2011.03.002

Cohen, W., \& Levinthal, D. (1989). Innovation and Learning: The Two Faces of R \& D. The Economic Journal 99(397):569. https://doi.org/10.2307/2233763

Coletti, M. (2010). Technology and industrial clusters: how different are they to manage? Science and Public Policy, 37(9), 679-688. https://doi.org/10.3152/030234210X12778118264413

Cooke, P. (2012). Relatedness, transversality and public policy in innovative regions. European Planning Studies, 20(11), 1889-1907. https://doi.org/10.1080/09654313.2012.723426

Cooke, P. (2014). Transversal or linear? Knowledge externalities and the complexity of knowledge interactions. In C. Antonelli (Ed.), Routledge Handbook of the Economics of Knowledge. Routledge.

Fiss, P. C. (2011). Building better causal theories: A fuzzy set approach to typologies in organization research. Academy of Management Journal, 54(2), 393-420. https://doi.org/10.5465/amj.2011. 60263120

Fitjar, R. D., \& Rodríguez-Pose, A. (2013). Firm collaboration and modes of innovation in Norway. Research Policy, 42(1), 128-138. https://doi.org/10.1016/j.respol.2012.05.009

Flick, U. (2018). Designing qualitative research (2nd edition). The SAGE qualitative research kit: / edited by Uwe Flick; 1st volume. Sage.

Fu, J. L. W., Revilla Diez, J., \& Schiller, D. (2013). Interactive learning, informal networks and innovation: Evidence from electronics firm survey in the Pearl River Delta. China. Research Policy, 42(3), 635-646. https://doi.org/10.1016/j.respol.2012.09.006

Glaser, B. G., \& Strauss, A. L. (1967). The discovery of grounded theory. Strategies for qualitative research (Observations). Chicago: Aldine.

González-Pernía, J. L., Parrilli, M. D., \& Peña-Legazkue, I. (2015). STI-DUI learning modes, firmuniversity collaboration and innovation. The Journal of Technology Transfer, 40(3), 475-492. https://doi.org/10.1007/s10961-014-9352-0

Greckhamer, T., Furnari, S., Fiss, P. C., \& Aguilera, R. V. (2018). Studying configurations with qualitative comparative analysis: Best practices in strategy and organization research. Strategic Organization, 16(4), 482-495. https://doi.org/10.1177/1476127018786487

Grillitsch, M., Schubert, T., \& Srholec, M. (2019). Knowledge base combinations and firm growth. Research Policy, 48(1), 234-247. https://doi.org/10.1016/j.respol.2018.08.009

Haus-Reve, S., Fitjar, R. D., \& Rodríguez-Pose, A. (2019). Does combining different types of collaboration always benefit firms? Collaboration, complementarity and product innovation in Norway. Research Policy, 48(6), 1476-1486. https://doi.org/10.1016/j.respol.2019.02.008

Holtskog, H. (2017). Forms of innovation-Insights from product development. Journal of the Knowledge Economy, 8(1), 63-76. https://doi.org/10.1007/s13132-015-0318-8

Isaksen, A., \& Karlsen, J. (2010). Different modes of innovation and the challenge of connecting universities and industry: Case studies of two regional industries in Norway. European Planning Studies, 18(12), 1993-2008. https://doi.org/10.1080/09654313.2010.516523

Isaksen, A., \& Karlsen, J. (2013). Can small regions construct regional advantages? The case of four Norwegian regions. European Urban and Regional Studies, 20(2), 243-257. https://doi.org/10.1177/ 0969776412439200

Isaksen, A., \& Trippl, M. (2017). Innovation in space: The mosaic of regional innovation patterns. Oxford Review of Economic Policy, 33(1), 122-140. https://doi.org/10.1093/oxrep/grw035

Jensen, M. B., Johnson, B., Lorenz, E., \& Lundvall, B. А. (2007). Forms of knowledge and modes of innovation. Research Policy, 36(5), 680-693. https://doi.org/10.1016/j.respol.2007.01.006

Johnson, B. (2010). Institutional Learning. In B.-A. Lundvall (Ed.), National systems of innovation: Toward a theory of innovation and interactive learning (pp. 23-46). Anthem Press. https://doi.org/ 10.7135/UPO9781843318903.003

Johnson, B., Lorenz, E., \& Lundvall, B. Å. (2002). Why all this fuss about codified and tacit knowledge? Industrial and Corporate Change, 11(2), 245-262.

Kline, S. J., \& Rosenberg, N. (1986). An overview of innovation. In The positive sum strategy: Harnessing technology for economic growth. (pp. 275-306). The National Academies Press. 
Kraus, S., Rigtering, J. P. C., Hughes, M., \& Hosman, V. (2012). Entrepreneurial orientation and the business performance of SMEs: a quantitative study from the Netherlands. Review of Managerial Science, 6(2), 161-182. https://doi.org/10.1007/s11846-011-0062-9

Laestadius, S. (1998). The relevance of science and technology indicators: the case of pulp and paper. Research Policy, 27(4), 385-395. https://doi.org/10.1016/S0048-7333(98)00050-X

Lenz, R., \& Glückler. J. (2020). Same same but different: regional coherence between institutions and policies in family firm succession. European Planning Studies, 1-20. https://doi.org/10.1080/09654313. 2020.1757041

Malecki, E. J. (2012). Regional Social Capital: Why it Matters. Regional Studies, 46(8), 1023-1039. https://doi.org/10.1080/00343404.2011.607806

Manniche, J. (2012). Combinatorial knowledge dynamics: On the usefulness of the differentiated knowledge bases model. European Planning Studies, 20(11), 1823-1841. https://doi.org/10.1080/09654313. 2012.723423

Martin, R., Moodysson, J., \& Zukauskaite, E. (2011). Regional innovation policy beyond 'best practice': Lessons from Sweden. Journal of the Knowledge Economy, 2(4), 550-568. https://doi.org/10.1007/ s13132-011-0067-2

Marx, A. (2006). Towards a more robust model specification in QCA: Results from a methodological experiment. Compass- Working Paper. http://www.compasss.org/wpseries/Marx2006.pdf

Mayring, P. (2002). Einführung in die qualitative Sozialforschung [Introduction to qualitative social research]. Beltz Verlag.

Mayring, P. (2010). Qualitative Inhaltsanalyse. Grundlagen und Techniken [Qualitative Content Analysis. Basics and technics]. Weinheim: Beltz Verlagsgruppe. Retrieved from http://www.contentselect.com/index.php?id=bib_view\&ean=9783407291424

Miles, M. B., \& Huberman, A. M. (1994). Qualitative data analysis: An expanded sourcebook (2. ed.). Sage.

Nunes, S., \& Lopes, R. (2015). Firm performance, innovation modes and territorial embeddedness. European Planning Studies, 23(9), 1796-1826. https://doi.org/10.1080/09654313.2015.1021666

OECD and European Commission. (2005). Oslo Manual: Guidelines for Collecting and Interpreting Innovation Data. (The Measurement of Scientific and Technological Activities). Paris. OECD. https://doi. org/10.1787/9789264013100-en

Ordanini, A., Parasuraman, A., \& Rubera, G. (2014). When the Recipe Is More Important Than the Ingredients. Journal of Service Research, 17(2), 134-149. https://doi.org/10.1177/1094670513513337

Parrilli, M. D., \& Elola, A. (2012). The strength of science and technology drivers for SME innovation. Small Business Economics, 39(4), 897-907. https://doi.org/10.1007/s11187-011-9319-6

Parrilli, M. D., \& Heras, H. A. (2016). STI and DUI innovation modes: Scientific-technological and context-specific nuances. Research Policy, 45(4), 747-756. https://doi.org/10.1016/j.respol.2016.01.001

Ragin, C. C. (2008). Redesigning social inquiry: Fuzzy sets and beyond. Univ. of Chicago Press.

Ragin, C. C. (2009). Fuzzy-set social science. Univ. of Chicago Press.

Ragin, C. C. (2017). User's Guide to Fuzzy-Set / Qalitative Comparative Analysis. . Irvine: Deparment of Sociology; University of California. www.fsqca.com

Rille-Pfeiffer, C. (2009). Kinder - jetzt, später oder nie?“" Generatives Verhalten und Kinderwunsch in Österreich, Schweden und Spanien auf Basis der Qualitative Comparative Analysis (QCA) [Children- now, later or never? Behavior and wish for child in Austria, Sweden and Spain using QCA] [Dissertation]. Universität Wien, Wien.

Rosenberg, N. (1982). Inside the Black Box: Technology and Economics.

Rutten, R. (2017). Beyond proximities. Progress in Human Geography, 41(2), 159-177. https://doi.org/ $10.1177 / 0309132516629003$

Rutten, R. (2019). Openness values and regional innovation: a set-analysis. Journal of Economic Geography, 19(6), 1211-1232. https://doi.org/10.1093/jeg/lby061

Rutten, R. (2020a). Applying and assessing large-N QCA: Causality and robustness from a critical realist perspective. Sociological Methods \& Research, 46, 004912412091495. https://doi.org/10.1177/ 0049124120914955

Rutten, R. (2020b). Comparing causal logics: A configurational analysis of proximities using simulated data. Zeitschrift Für Wirtschaftsgeographie, 1-15. https://doi.org/10.1515/zfw-2019-0023

Schneider, C. Q., \& Wagemann, C. (2012). Set-theoretic methods for the social sciences. Cambridge University Press. https://doi.org/10.1017/CBO9781139004244 
Schreier, M. (2007). Qualitative Stichprobenkonzepte [Qualitative Sampling]. In G. Naderer \& E. Balzer (Eds.), Qualitative Marktforschung in Theorie und Praxis 15, 231-245. Wiesbaden: Gabler. https:// doi.org/10.1007/978-3-8349-9262-8_12

Strambach, S., \& Klement, B. (2012). Cumulative and combinatorial micro-dynamics of knowledge: The role of space and place in knowledge integration. European Planning Studies, 20(11), 18431866. https://doi.org/10.1080/09654313.2012.723424

Thomä, J. (2017). DUI mode learning and barriers to innovation-A case from Germany. Research Policy, 46(7), 1327-1339. https://doi.org/10.1016/j.respol.2017.06.004

Thomä, J., \& Zimmermann, V. (2019). Interactive learning — The key to innovation in non-R\&D-intensive SMEs? A cluster analysis approach. Journal of Small Business Management, 1-30. https://doi.org/ 10.1080/00472778.2019.1671702

Thompson, P. (2010). Learning by Doing. In B. H. Hall \& N. Rosenberg (Eds.), Handbook of the economics of innovation (Vol. 1, pp. 429-476). North Holland. https://doi.org/10.1016/S0169-7218(10) $01010-5$

Trippl, M. (2011). Regional innovation systems and knowledge-sourcing activities in traditional industries-Evidence from the Vienna food sector. Environment and Planning a, 43(7), 1599-1616. https://doi.org/10.1068/a4416

Trott, P., \& Simms, C. (2017). An examination of product innovation in low- and medium-technology industries: Cases from the UK packaged food sector. Research Policy, 46(3), 605-623. https://doi. org/10.1016/j.respol.2017.01.007

Valaei, N., Rezaei, S., \& Ismail, W. K. W. (2017). Examining learning strategies, creativity, and innovation at SMEs using fuzzy set Qualitative Comparative Analysis and PLS path modeling. Journal of Business Research, 70, 224-233. https://doi.org/10.1016/j.jbusres.2016.08.016

von Hippel, E. (2005). Democratizing innovation: The evolving phenomenon of user innovation. Journal Für Betriebswirtschaft, 55(1), 63-78. https://doi.org/10.1007/s11301-004-0002-8

Publisher's Note Springer Nature remains neutral with regard to jurisdictional claims in published maps and institutional affiliations. 